\title{
TEXTURE DEVELOPMENT AND TEXTURE INHOMOGENEITIES IN A HOT-ROLLED CuZnAI SHAPE MEMORY ALLOY
}

\author{
N.J. PARK and H.J. BUNGE \\ Department of Physical Metallurgy, TU Clausthal Grosser Bruch 23, D-3392 Clausthal-Zellerfeld, \\ Germany
}

\section{Abstract}

The texture development in a hot rolled $\mathrm{Cu}-14.2 \mathrm{wt} . \% \mathrm{Zn}-5.6 \mathrm{wt} . \% \mathrm{Al}$ in the surface and centre of the sheet was studied. The observed texture in the centre of the sheet can be understood in terms of the $\{001\}\langle 011\rangle$ and $\{211\}\langle 011\rangle$ hot rolling texture in the austenite phase and the reported crystallographic orientation relationships between monoclinic martensite and b.c.c. austenit. In the surface of the sheet the texture was developed with the influence of shear deformation. Therefore in the martensitic phase only the orientation components were observed which were originated from the $\{001\}\langle 011\rangle$ of the b.c.c. phase. Besides the variant selection of the crystal orientation was observed during the pahse transformation in the surface of the sheet.

\section{Introduction}

The martensitic transformation of shape memory alloys is crystallographically strictly oriented. Hence, in polycrystalline materials the shape memory effects depend on the texture of the material, i.e. the orientation distribution function, $O D F$, of its crystallites. Furthermore, the texture of the martensitic phase is inherited from that of the high-temperature austenitic phase taking the crystallographic orientation relationship and the relative frequency of its symmetry variants (variant selection) into account.

In the present paper the texture of a $\mathrm{Cu} \mathrm{Zn} \mathrm{Al}$ shape memory alloy was studied in the martensitic state after it had been hot rolled in the austenitic state. After this treatment, strong differences of the texture of the surface and in the interiour of the material were found which have an influence on the macroscopic properties of the materials.

\section{Experimental}

The material with the composition $\mathrm{Cu}-14.2 \mathrm{wt} \% \mathrm{Zn}-5.6 \mathrm{wt} \% \mathrm{Al}$ was melted in a medium frequency induction furnace and hot rolled at $750^{\circ} \mathrm{C}$ in steps of $20 \%$ to a final thickness of $1 \mathrm{~mm}$ equivalent to $96 \%$ total rolling reduction. Thereby several intermediate annealing treatments at $750^{\circ} \mathrm{C}$ were necessary. After that the material was cooled down to room temperature whereby it transforms from b.c.c. to monoclinic. The transformation temperatures were found to be $M_{s}=115^{\circ} \mathrm{C}, M_{f}=99^{\circ} \mathrm{C}, A_{s}=119^{\circ} \mathrm{C}, A_{f}=128^{\circ} \mathrm{C}$. The lattice parameters of the monoclinic 
phase were determinated by $X$-ray diffraction. They are $a=4.457 \AA, b=5.326 \AA, c=38.184 \AA$, $\beta=88.79^{\circ}$. The monoclinic angle $\beta$ deviates only $1.21^{\circ}$ from $90^{\circ}$. Hence, the reflections $(h k l)$ and $(h k \bar{l})$ are systematically overlapped. This was not resolved in the following texture measurement.

Samples for texture measurement were prepared from the surface and the middle of the sheet.

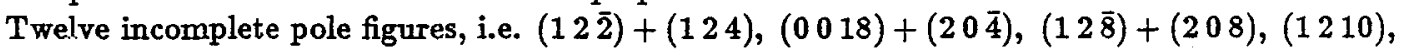

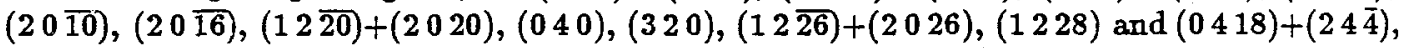
were measured in steps $\Delta \alpha=5^{\circ}, \Delta \beta=3.6^{\circ}$ up to $\alpha_{\max }=70^{\circ}$ using $C o K_{\alpha}$-radiation.

The complete orientation distribution function, $O D F$, was calculated from these pole figures using an iterative positivity method $/ 1,2,3 /$ with a maximun series expansion degree $\lambda_{\text {max }}=23$. With the same method also inverse pole figures of the rolling and normal directions were obtained. Since the $(h k l)-(h k \bar{l})$ superposition was not resolved here the obtained preferred orientations are superpositions of two orientations $\{h k l\}\langle u v w\rangle$ and $\{h k \bar{l}\}\langle u v w\rangle$ each. This has to be taken into consideration in the discussion of the results.

\section{$3 \quad$ Results and Discussion}

In Fig.1, three of the twelve measured pole figures are shown for the sheet middle plane and the surface. There are quite different. The $O D F$ were calculated using all measured pole figures. They are given in Fig.2 a,b. Also the $O D F$ of the middle plane and the sheet surface are quite different. The maximum density orientations of the two textures are summarized in Tab.1.

In the middle texture, three stronger components $M 1, M 2, M 3$ are found besides three weaker ones M4, M5, M6. At the surface, only three main components S1, S2, S3 can be distinguished. Taking the crystallographic orientation relationships between b.c.c. austenite and monoclinic martensite $/ 4,5 /[100]_{M}\left\|\langle 110\rangle_{A},[010]_{M}\right\|\langle 100\rangle_{A},[001]_{M} \|\langle 504\rangle_{A}$ into account, the corresponding orientations of austenite can be estimated from the observed martensite orientations. These orientations are also given in Tab.1. It is seen that they cluster around two main austenite orientations i.e. $\left\{\begin{array}{lll}0 & 0 & 1\end{array}\right\}\left\langle\begin{array}{lll}1 & 1 & 0\end{array}\right)$ and $\left\{\begin{array}{lll}2 & 1 & 1\end{array}\right\}\left\langle\left(\begin{array}{lll}0 & 1 & 1\end{array}\right)\right.$. This is in good agreement with Dillamore and Roberts' theory /6/ of rolling texture formation in b.c.c matals with equal amount of primary and cross slip.

Using the above - mentioned orientation relationships between austenite and martensite, the original austenite texture can be recalculated from the observed martensite texture $/ 1 /$. Thereby it is assumed that all crystallographically equivalent martensite variants are really formed from any starting austenite orientation. If one assumes that this was fulfulled in the sheet middle plane, then the estimated austenite texture Fig. 3 is obtained. It shows the mean orientation $\left\{\begin{array}{lll}0 & 1\end{array}\right\}\langle 110\rangle$ which is connected with the orientation $\{211\}\langle 011\rangle$ by continuous spread range. A second weaker spread range also extends from that latter orientation towards $\left\{\begin{array}{lll}1 & 1 & 1\end{array}\right\}\langle 211\rangle$. The calculated austenite texture thus resembles strongly to the rolling textures found in several b.c.c. metals.

The texture of the sheet surface (Fig.2 b) deviates strongly from that in the sheet middle plane (Fig.2 a). This effect can also be seen in the inverse pole figures of rolling and normal direction (Fig.4a, b and 5a, b) calculated from the two textures in Fig.2 a,b. Considering the main features of these inverse pole figures, in the surface texture, some of the orientations found in the interior are missing. This may be attributed to variant selection in the above - mentioned orientation relationship. Hence, in Fig. 6 a and $b$ all martensite directions correspendings to $\langle 110\rangle$ austenite 
in the rolling direction as well as to $\left\{\begin{array}{lll}1 & 0 & 0\end{array}\right\}$ and $\left\{\begin{array}{lll}2 & 1 & 1\end{array}\right\}$ austenite in normal direction were calculated. These calculated directions agree quite well with the inverse pole figures for the sheet middle plane whereas some of them are missing in the surface. Hence, it may be concluded that in the surface the continuity condition during martensitic transformation can be fullfilled with fewer martensite variants than in the interior where more or less all crystallographically equivalent varients are being formed.

A second possible effect, however, can also not be excluded. Rolling texture formation is often a lower number different in the interior and at the surface of a rolled sheet. This is due to a larger shear component in the surface which occours as a consequence of roller friction $/ 7,8 /$. Hence, in the surface texture the orientations derived from $\left\{\begin{array}{lll}0 & 0 & 1\end{array}\right\}\left\langle\begin{array}{lll}1 & 1 & 0\end{array}\right)$ are dominant, whereas those derived from $\left\{\begin{array}{lll}2 & 1 & 1\end{array}\right\}\left\langle\begin{array}{lll}0 & 1 & 1\end{array}\right)$ are much weaker.

\section{References}

1. H.J. Bunge, Texture Analysis in Material Science, 1982, Butterworth, London

2. M. Dahms, H.J. Bunge, J. Appl. Cryst., 222, (1989), 439-447

3. N.J.Park, H.J. Bunge, Z. Metallkunde, $\underline{81}$, (1990), 636-645

4. K. Otsuka, K. Shimizu, Int. Metals Rev., 31, (1986), 93-114

5. K. Adachi, J. Perkins, C.M. Wayman, Acta Met., 36, (1988), 1343-1364

6. I.L. Dillamore, W.T. Roberts, Acta Met., $\underline{12}$, (1964), 281-293

7. I.L. Dillamore, W.T. Roberts, J.Inst. Met., $\underline{92}$, (1963-64), 192-199

8. W.Österle, H. Wever, Z. Metallkunde, 프, (1981), 230-237

Table 1: Orientation components of $96 \%$ hot rolled CuZnAl-alloy

\begin{tabular}{|c|ccc|c|c||c|}
\hline component & $\varphi_{1}$ & $\Phi$ & $\varphi_{2}$ & $f(g)$ & $\begin{array}{c}\text { original } \\
\{h k l\}\langle u v w\rangle \\
\text { of the martensite }\end{array}$ & $\begin{array}{c}\{h k l\}\langle\text { uvw } \\
\text { of the b.c.c. phase }\end{array}$ \\
\hline \multicolumn{8}{|c|}{ middle texture of the sheet } \\
\hline M1 & $0^{\circ}$ & $82^{\circ}$ & $0^{\circ}$ & 31.7 & $\{011\}\langle 100\rangle$ & $\{191\}\langle 101\rangle$ \\
M2 & $90^{\circ}$ & $90^{\circ}$ & $0^{\circ}$ & 23.1 & $\{010\}\langle 001\rangle$ & $\{010\}\langle 504\rangle$ \\
M3 & $45^{\circ}$ & $45^{\circ}$ & $90^{\circ}$ & 21.6 & $\{109\}\langle 9.10 .1\rangle$ & $\{17.0 .1\}\langle 1.20 .17\rangle$ \\
M4 & $0^{\circ}$ & $55^{\circ}$ & $0^{\circ}$ & 18.8 & $\{015\}\langle 100\rangle$ & $\{121\}\langle 101\rangle$ \\
M5 & $67^{\circ}$ & $32^{\circ}$ & $160^{\circ}$ & 15.2 & $\{1.3 .37\}\langle 10.9 .1\rangle$ & $\{533\}\langle 10.9 .1\rangle$ \\
M6 & $30^{\circ}$ & $73^{\circ}$ & $120^{\circ}$ & 14.9 & $\{10.7 .30\}\langle 10.10 .1\rangle$ & $\{16.9 .10\}\langle 0.10 .9\rangle$ \\
\hline \hline \multicolumn{8}{|c|}{ surface texture of the sheet } \\
\hline S1 & $87^{\circ}$ & $90^{\circ}$ & $0^{\circ}$ & 13.6 & $\{010\}\langle 102\rangle$ & $\{010\}\langle 4.03\rangle$ \\
S2 & $5^{\circ}$ & $78^{\circ}$ & $0^{\circ}$ & 9.8 & $\{023\}\langle 100\rangle$ & $\{161\}\langle 101\rangle$ \\
S3 & $60^{\circ}$ & $40^{\circ}$ & $90^{\circ}$ & 6.3 & $\{1.0 .10\}\langle 10.6 .1\rangle$ & $\{100\}\langle 023\rangle$ \\
\hline
\end{tabular}



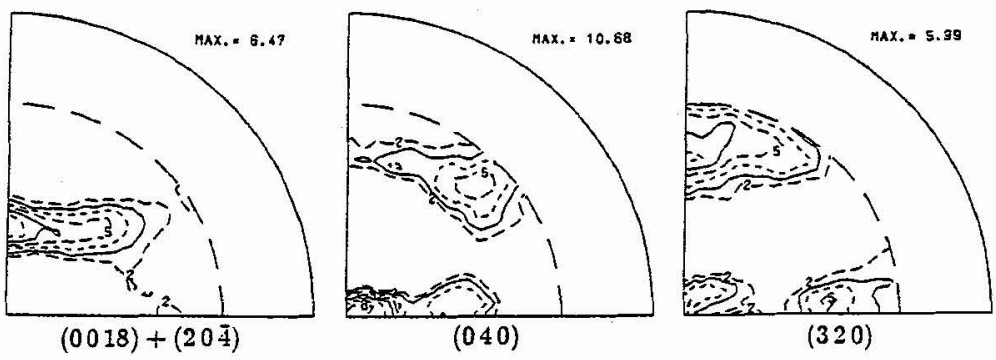

(a)

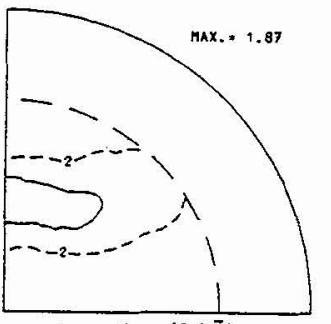

$(0018)+(20 \overline{4})$

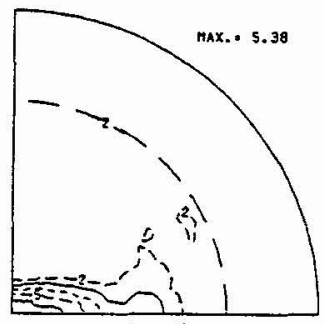

(040)
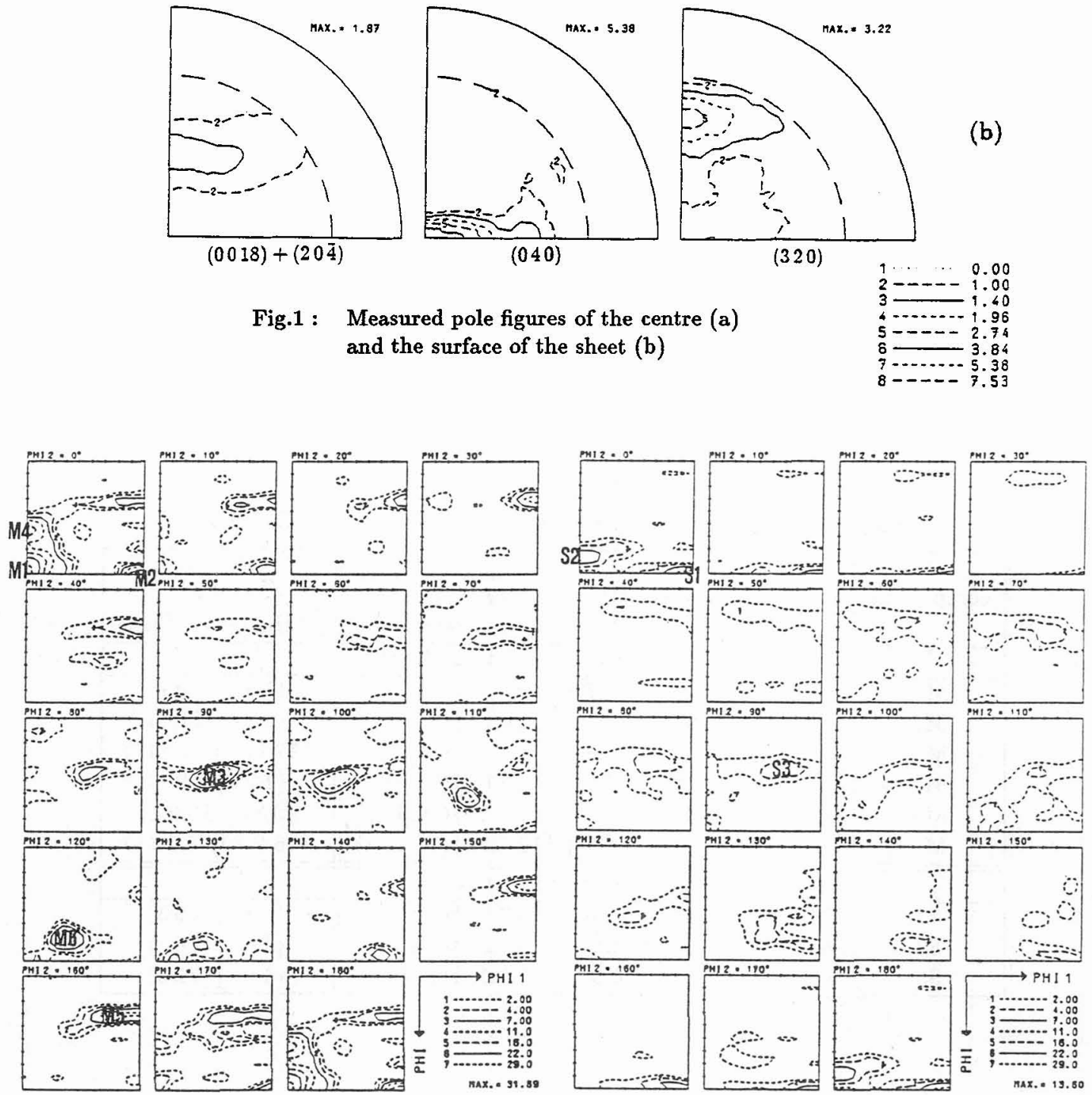

Fig.2a : ODF of a hot rolled $\mathrm{Cu}-14.2 \% \mathrm{Zn}-5.6 \% \mathrm{AI}$ of the centre of the sheet

Fig.2b : ODF of a hot rolled $\mathrm{Cu}-14.2 \% \mathrm{Zn}-5.6 \% \mathrm{Al}$ of the surface of the sheet 

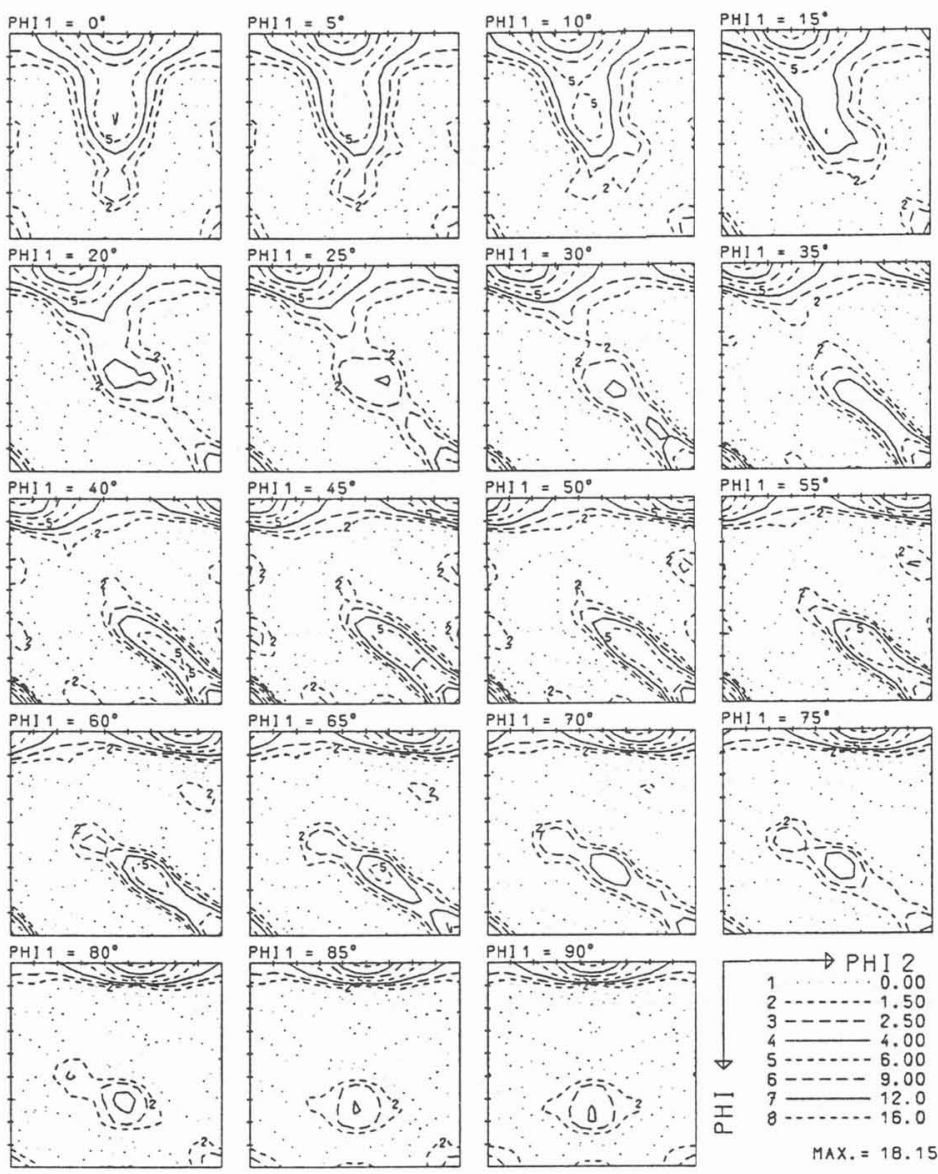

Fig.3 : Calculated initial textur of the b.c.c. austenit phase in the centre of the sheet 
[010]

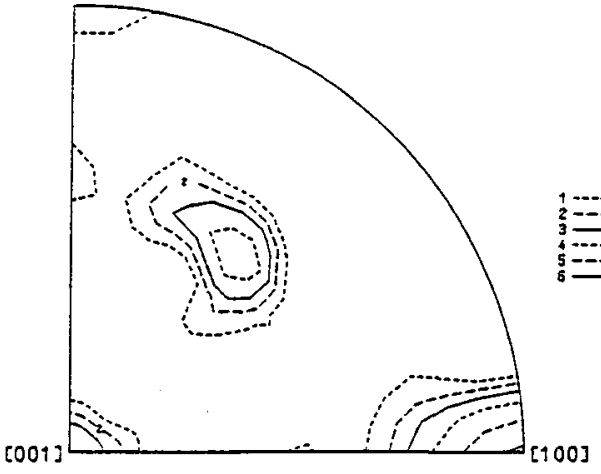

Fig.4a : Inverse pole figure for the rolling direction of the centre of the sheet

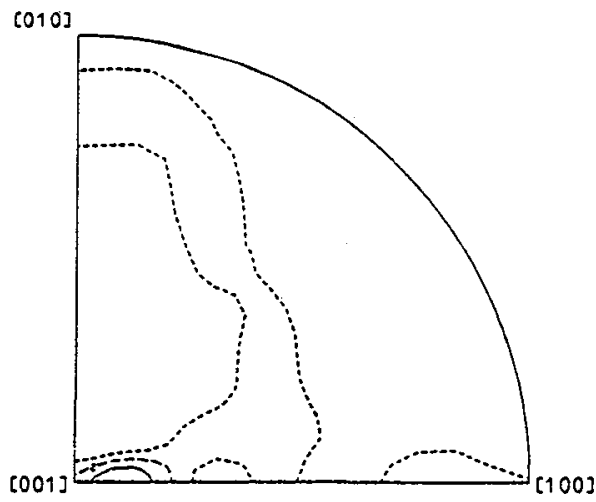

Fig.5a : Inverse pole figure for the rolling direction of the surface of the sheet

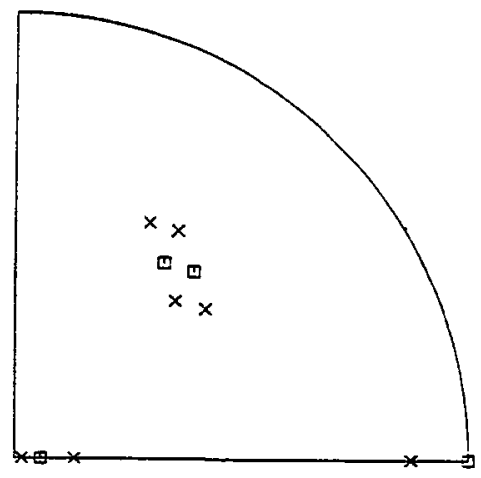

[010]

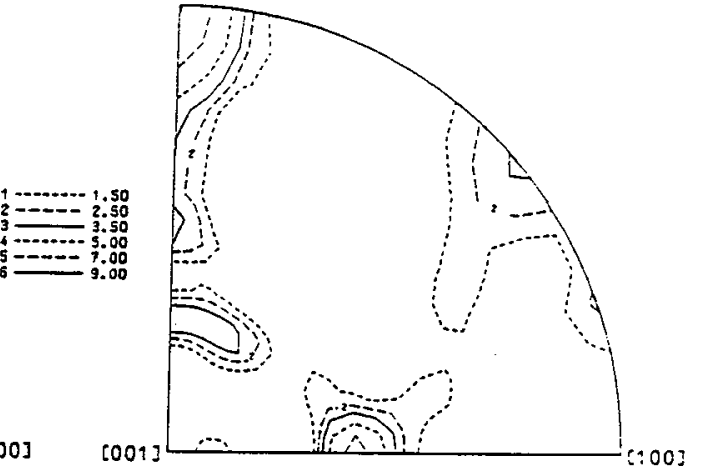

Fig.4b : Inverse pole figure for the normal direction of the centre of the sheet

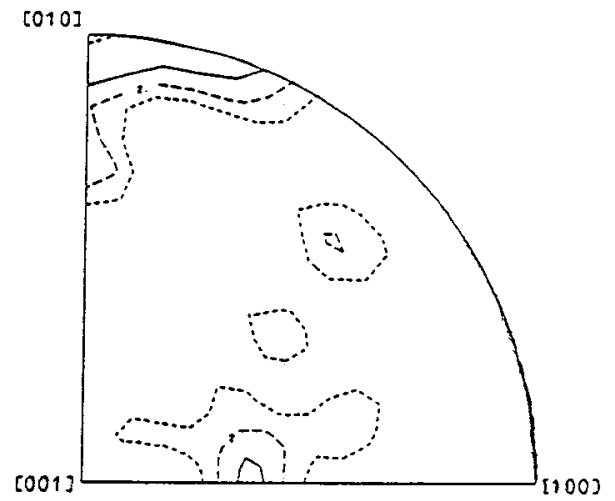

Fig.5b : Inverse pole figure for the normal direction of the surface of the sheet

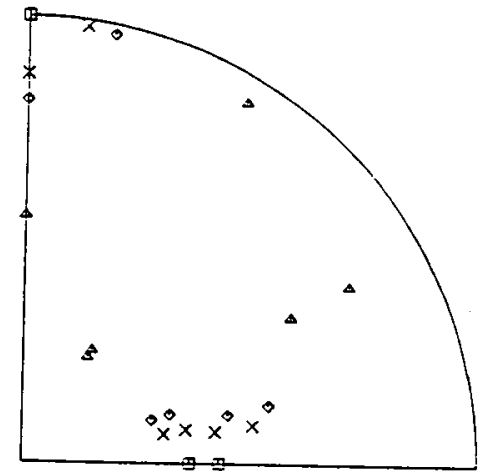

Fig.6a : All variants of $\langle 110\rangle_{A}(\square)$ and $\langle 430\rangle_{A}(x)$ Fig.6b : All variants of the plane normals of $\{100\}_{A}(\square),\{211\}_{A}(\triangle),\{911\}_{A}(x)$ and $\{611\}_{A}(\diamond)$ 